\title{
Depression and Anxiety Observed In Parents of Children Diagnosed with Chronic Neurological Diseases
}

Öz

Amaç: Kronik hastalık tanımı, "geriye dönüşü olmayan, kalıcı yetersizliğe neden olabilen patolojik değişiklikler ile oluşan ve hastanın rehabilitasyonu için özel eğitim, uzun süre bakım, gözetim ve denetim gerektirebilecek durum" olarak yapılmaktadır. Hasta olan ailenin en değerli varlığı çocuk ise bu durum tüm aile için gerçek travma kaynağı olmaktadır. Dolayısıyla bu çalışmanın amacı; hasta çocukların ebeveynlerinde depresyon ve anksiyete oranının içinde bulunulan duruma bağlı olarak yüksek olduğunu göstermek ve psikolojik destek gereksiniminin gerekliliğine dikkat çekmektir.

Yöntem: Bu araştırma, İstanbul Tıp Fakültesi Çocuk Nörolojisi Bilim Dalına başvuran hasta çocukIarın anne, baba ve yakınları ile Istanbul ili Şişli ilçesi Merkez Aile Sağlığı Merkezine başvuran sağlıkıı çocuk/çocuklara sahip olan ebeveynlerden katılmayı kabul eden bireylerle yapılmıştır. Beck Depresyon Ölçeği (BDÖ), Beck Anksiyete Ölçeği (BAÖ) ve araştırmacı tarafından hazırlanan aile görüşme formu kullanılmıştır. Katıımı kabul eden bireylerden onam alınarak yüz yüze görüşme tekniği uygulandı. Katılımcıların cevapları; katılımcı ya da araştırmacı tarafından forma kaydedilerek, $B D O ̈$ ve $B A O ̈$ kapsamındaki soruların seçeneklerinden kendileri için uygun olanları işaretlemeleri istenmiştir.

Bulgular: Araştırmaya katılanlardan çocukta kronik nörolojik hastalık olan vaka grubu $(n=60)$ ile çocukta kronik nörolojik hastalık olmayan ebeveynlerin oluşturduğu kontrol grubu $(n=60)$ depresyon ve anksiyete düzeyleri açısından karşılaştırıldığında anlamlı bir farklılık olmadığı görülmüşsür $(t=1.273 p>0.05)$.

Sonuç: Hem anksiyete hem depresyon düzeylerinin arasında anlamlı bir farklılık olmaması, ancak her iki grupta da hem anksiyete hem depresyonun yüksek oranda varlığı daha ileri düzeyde yapılabilecek araştırmalara gerek duyulduğunu göstermektedir.

Anahtar kelimeler: Depresyon, anksiyete, kronik nörolojik hastalık, aile

\section{ABSTRACT}

Objective: Chronic disease is defined as" a condition caused by irreversible pathological changes that may lead to permanent disability and may require special education, long-term care, supervision and control for the rehabilitation of the patient". If the patient is the child who is the most valuable asset of the family, this situation is a source of real trauma for the entire family. . Hence; this study aimed to demonstrate that parents of children with chronic neurological disease have higher depression and anxiety levels depending on the circumstances they are involved and draw attention to the necessity of psychological support for these families

Method: This study was conducted with the parents and relatives of the sick children who applied to the Department of Pediatric Neurology of Istanbul Medical Faculty and the parents and relatives of healthy children who applied to the family health center Şişli in Istanbul. Beck Depression Inventory (BDI), Beck Anxiety Inventory (BAI) and family interview form prepared by the researcher were used in this study. Informed consent was obtained from the participants and face to face interview technique was applied. The responses of the participants; were written down by the participant or researcher on the form and they were asked to mark the options of the questions within the scope of BDI and BAI.

Results: In this survey any significant difference was not observed between the group of parents of children with (patient group: $n=60$ ) and without chronic neurological disease (control group: $n=60)(t=p 1.273 p>0.05)$.

Conclusion: Lack of any significant difference between anxiety and depression levels of the case and control groups, but still higher anxety and depression levels in both groups demonstrate that further and more sophisticated studsses should be performed on this issue.

Keywords: Depression, anxiety, chronic neurological disease, family

$\begin{array}{r}\hline \text { Alındığı tarih: } 26.02 .2019 \\ \text { Kabul tarihi: } 11.06 .2019 \\ \text { Yayın tarihi: } 31.08 .2019 \\ \hline\end{array}$

Ayşen Yenici T.C. İstanbul Şişli Meslek Yüksekokulu Çocuk Gelişimi Programı

İstanbul - Türkiye

mapcot@hotmail.com ORCID: 0000-0003-2989-643X

N. Aydınlı 0000-0003-0492-3411 M. Çalışkan 0000-0003-1641-9191 i. Ü. İstanbul Tıp Fakültesi Çocuk Sağlığı ve Hastalıkları ABD Çocuk Nörolojisi Bilim Dalı istanbul - Türkiye 


\section{Giriş}

Anne baba ve çocuklardan oluşan toplumun en küçük birimi olarak tanımlanan ailede çocuk özen gösterilen, çok sevilen ve en çok değer verilen varlık olarak tüm ilgiyi üzerine çekmektedir. Bu değerli varIığın hastalanması aileyi olumsuz etkilemekte, hele söz konusu hastalık her zaman tamamen iyileşme, eski sağlığına kavuşması mümkün olmayabilecek kronik bir hastalık ise ve başkalarının sürekli desteğini, bakımını gerektirebilecek yeti kayıpları olabilecekse olumsuz etkiler aile için psikolojik bir travmaya dönüşebilecektir. Hastalığın türüne ve şiddetine göre hastaneye yatışların olması, bu durumun yinelenmesi ailenin sosyal yaşamdan uzak kalmasına neden olur. Bunun yanı sıra tedavinin gerektireceği giderler, yinelenen tedavi ritüelleri, beslenme gereksinimleri ve bu durumun ne kadar süreceği konusundaki belirsizlik psikolojik travma olasılığını daha da yükseltmektedir. Anne-baba bu durumda ayrıca yoğun olarak çocuklarının eski hâline dönüp dönemeyeceği hatta yaşayıp yaşayamayacağı ile ilgili endişeler duyar.

Kronik hastalık tanımı, "geriye dönüşü olmayan, kalıCl yetersizliğe neden olabilen patolojik değişiklikler ile oluşan ve hastanın rehabilitasyonu için özel eğitim, uzun süre bakım, gözetim ve denetim gerektirebilecek durum" olarak yapılmaktadır.

Her türlü bedensel hastalık kişinin vücut bütünlüğüne ve yaşam kalitesine doğrudan travmatik bir etki yapar. Böyle bir hastalık tanısı ile karşılaşıldığında tanının doğruluğu, hastalığın geleceği ve tedavi olasıIıkları hakkında ciddi kaygılar duyulur. Nörolojik hastalıklarda ise hem beden fonksiyonları hem de zihin fonksiyonları etkilenebildiğinden kişi, ailesi ve yakın çevresi için daha dramatik sonuçlar ortaya çıkmaktadır ${ }^{(1)}$. Yapılan araştırmalarda, kronik hastalığın diğer aile üyelerinde stres yarattığı vurgulanmaktadır ${ }^{(2)}$.

Yapılan bir çalışmada, anne ve babanın çocuğuna kronik hastalık tanısı konulduğunda psikolojileri aşağıdaki gibi sıralanmıştır (3).

- Şok, akut korku ve anksiyete, yadsıma
- Kızgınlık ve içerleme duygusu

- Kendisini veya eşini suçlama

- Durumu kabullenme

Ailede genel olarak anneler çocuğun bakımı gereksinimlerini karşılamayı üstlendikleri ve hastane kalışlarında çocuğun yanında oldukları için çocuktaki kronik hastalıklarının aile üzerindeki etkilerini araştıran çalışmalar da çoğunlukla anneler üzerine yoğunlaşmıştır. Bu annelerde sağlıklı çocuğu olan annelere göre depresyon ve anksiyetenin daha fazla görülebilceği düşünülmektedir.

Çocuklardaki kronik hastalığın şiddeti, çocuğun yaşı, tıbbi yardım gereksiniminin fazla olması (Örn, yineleyen ameliyatlar), ailenin ekonomik düzeyi, annebabaların eğitim düzeyleri, meslekleri, ailenin sosyal güvencesinin olup olmaması gibi çeşitli etkenler anne-babanın hastalığı kabullenme düzeyini, algılama şeklini, çocuğa uyumunu ve stres düzeylerini etkilemektedir ${ }^{(4)}$.

Hastalığın türüne, şiddetine, tedavi edilebilir bir hastalık ise tedavinin zor ve uzun bir süreç olup olmamasına, durumla ilgili belirsizliklere göre ailede yaşanan ruhsal stres anksiyete ve/veya depresyon belirtilerinin ortaya çıkmasına yol açmaktadır.

Anksiyete; iç sıkıntısı, kaygı, bunaltı gibi sözcüklerle anlatılmaya çalışılan, yaşamı tehdit eden ya da tehdit şeklinde algılanan, rahatsız edici, endişe ve korku duygusudur. İçsel ya da dış dünyadan bir tehlike olasılığı ya da kişi tarafından tehlikeli olarak algılanıp yorumlanan herhangi bir durum karşısında yaşanan duygudurumdur ${ }^{(5)}$.

Anksiyete duygusu, olaylara içerdikleri tehlikelerle orantısız, uygunsuz ve abartılmış yanıtlar verilmesine neden olabilmektedir. Kişinin, kendine olan güven duygusunun yetersizliği ya da kendisi ile ilgili yeteneksizlik, beceriksizlik gibi olumsuz yorumların fazlaIığı oranında, uygunsuz yanıtlar verme olasılığı da daha çok olacaktır. Ayrıca tehlikeli uyaran ortadan kalktıktan sonra bile kişinin savunucu tutumu ve 
uygunsuz yanıtları devam edebilecektir ${ }^{(6)}$.

Anksiyete durumunda kişide genel bir huzursuzluk, nedeni ve nesnesi bilinmeyen bir korku, geçici unutkanlıklar, dikkat dağınıklı̆̆ı, kan basıncının yükselmesi, çarpıntı, gerginlik, nefes almada güçlük gibi pek çok yakınma vardır.

Depresyon ise insanın yaşama istek ve zevkinin kaybolduğu, kişinin kendisini derin bir keder içerisinde hissettiği, geleceğe ilişkin kötümser, karamsar düşünceler, geçmişe ilişkin yoğun pişmanlık, suçluluk duygu ve düşüncelerinin taşındığı, bazen ölüm düşüncesi, bazen intihar girişimi ve sonuçta ölümün olabildiği, uyku, iştah, cinsel istek ile ilgili fizyolojik bozuklukların olduğu bir hastalıktır ${ }^{(7)}$.

Depresif bir duygudurum ile ilgili zevk almanın kaybı depresyonun anahtar sözcükleridir. Depresif durumdaki kişiler kendilerini sıkıntılı, umutsuz ya da değersiz hissettiklerini söylerler ve ailelerinden, arkadaşlarından ve daha önce ilgilendikleri etkinliklerden uzak dururlar ${ }^{(8)}$. Herhangi bir aktiviteye başlamak, sürdürmek ya da tamamlamak konusunda isteksizdirler. Sıkıntılı ve üzgündürler, konuşmak istemezler, olumsuz ve karamsar bir ruh hâli içindedirler, bedensel yakınmaları vardır.

Genellikle depresyon ve anksiyetenin birlikte görülmesi sık rastlanan bir durumdur. Depresyon ve anksiyete arasındaki ilişki uzun zamandır tartışılmaktadır. Belirtilerin örtüşmesi nedeniyle tanı, araştırma ve tedavi konusunda güçlüklerle karşılaşılmıştır. Anksiyete ve depresyonun birlikte görüldüğü durumlarda başarılı tedavi için en önemli unsur eştanılı durumların erkenden saptanmasıdır ${ }^{(9)}$.

Kronik hastalık süreklilik gösteren bir durumdur. Bu nedenle de bu durumdaki bir çocuğa sahip anne baba için çocuğun bakımı ve gereksinimlerinin karşılanması oldukça zor geçen uzun bir dönem olabilmektedir. Tip biliminin ilerlemesi ve yeni yapılan çalışmalarla çocukluk çağındaki kronik ve ölümcül hastalıklarda yaşam süreleri uzamaktadır. Son çalış- malar, kronik hastalıklı çocukların mortalite oranlarının düştüğünü ve bu çocukların $\% 90$ 'ının erken erişkinlik dönemine ulaşabildiğini göstermektedir ${ }^{(10)}$. Yaşam süresinin uzaması ile birlikte; hasta çocuk ve ailesi, hastalığın getirdiği psikososyal etkilere daha uzun süre maruz kalmaktadırlar. Kronik hastalığı olan çocuklarda ve ailelerinde depresyon ve anksiyete düzeylerinin arttığını ve ailelerin sağlıklı çocuğa sahip ailelere göre daha çok psikososyal desteğe gereksinim duyduğunu bildiren çalışmalar bulunmaktadır ${ }^{(2)}$.

Stresle baş etmede özellikle zihinsel düzeyde yetersiz kalan bireylerde yaşanan stresin etkileri; korku, endişe, üzüntü, çaresizlik, umutsuzluk gibi duygusal sorunlara sonuç olarak anksiyete ve depresyona yol açmakta, anksiyete ve depresyon da çevresel faktörlerin daha da stres verici olarak algılanmasına neden olmaktadır ${ }^{(11)}$

Hasta bir çocuk için anne babasının yanında olması çok önemlidir, fakat bu durum ailenin sağlıklı bir şekilde var olmasına engel olabilmekte, psikolojik sıkıntılar yaşamasına neden olabilmektedir. Bu nedenle araştırma; kronik nörolojik hastalığı olan çocuklara sahip anne babalardaki depresyon ve anksiyete düzeyini belirlemek ve içinde bulunulan duruma bağlı olarak depresyon ve anksiyete düzeyinin yüksek olduğunu göstermek ve psikolojik destek gereksiniminin gerekliliğine dikkat çekmek amacıyla planlanmıştır.

\section{GEREÇ ve YÖNTEM}

Çalışma, 1 Nisan 2013-31 Temmuz 2013 tarihleri arasında İstanbul Üniversitesi Tıp Fakültesi Çocuk Sağığı ve Hastalıkları Anabilim Dalında Çocuk Nörolojisi Servisinde yatan ve poliklinik hizmetleri için başvuran 0-18 yaş arası hasta çocukların annebabaları, yakınları ve yanında eşlik edenler ve İstanbul ili Şişli ilçesi Merkez ASM'ye başvuranlar ve yanlarındaki kişilerden 0-18 yaş arası sağlıklı çocuğa/çocuklara sahip olan ebeveynlerden katılmayı kabul edenler ile yapılmıştır. Çalışmamıza alınan vaka grubu; çocuklarda rastlanma sıklığı en yüksek olan kronik nörolo- 
jik hastalıklar olan epilepsi, Multipl Skleroz (MS), Guillian-Barre Sendromu (GBS), subakut sklerozan panensefalit (SSPE), Akut Dissemine Ensefalomiyelit (ADEM), musküler distrofi tanısı almış ya da şüphesiyle tetkikte olan çocukların anne ve/veya babalarıdir.

Söz edilen kronik nörolojik hastalıklara sahip 30 çocuğun anne-babalarına ve kontrol grubu olarak alınan kronik nörolojik hastalığı olmayan 30 çocuğun anne-babalarına poliklinik başvuruları sırasında veya hastanede yatarak tetkik ve tedavi gördükleri ya da takipte oldukları veya bu kişilere eşlilk ettikleri dönemde ulaşılmıştır.

Bu araştırmada, katılımcıların sosyodemografik özelliklerini belirlemek için araştırmacı tarafından hazırlanmış Aile Görüşme Formu, depresif belirtileri araştırmak için Beck Depresyon Ölçeği (BDÖ), anksiyete belirtilerini araştırmak için de Beck Anksiyete Ölçeği (BAÖ) kullanılmıştır. Aile Görüşme Formu araştırmacı tarafından ailelere bilgi verilip onamları alındıktan sonra yüz yüze görüşme tekniği ile uygulanıp, katıIımcıların verdikleri cevaplar katılımcı ya da araştırmacı tarafından forma kaydedilmiş, sonrasında BDÖ ve BAÖ’lerdeki soruların seçeneklerinden kendileri için uygun olanları işaretlemeleri istenmiştir.

Aile Görüşme Formunda, ailelerin sosyodemografik bilgileri; yaşları, yakınlık dereceleri, eğitim düzeyleri, çalışma durumları, gelir düzeyleri, medeni durumla$\mathrm{rl}$, daha öncesinden kendisi ya da aileden birinin psikiyatrik hastalık tanısı alıp almadıkları, çocuklarının hastalıkları ile ilgili bilgiler ve kendileri için psikolojik destek isteyip istemedikleri sorgulanmıştır.

Yirmi bir maddelik bir kendi kendini değerlendirme ölçeği olup, depresif semptomları ve karakteristik yaklaşımları ölçmekte kullanılan Beck Depreyon Ölçeği ile katılımcıların depresyon düzeyi belirlendi ve kullanılan ölçekte 10 puandan itibaren depresyon belirtileri var olarak değerlendirildi.

Yirmi bir maddelik bir kendi kendini değerlendirme ölçeği olan Beck Anksiyete Ölçeği ile katılımcıların anksiyete düzeyi belirlendi. Kullanılan ölçekte 8 puandan itibaren anksiyete belirtileri var olarak değerlendirildi.

Çalışmada elde edilen bulgular değerlendirilirken, istatistiksel analizler için SPSS (Statistical Package for Social Sciences) 21 programı kullanıldı. Niceliksel verilerin karşılaştırılmasında iki grup durumunda, parametrelerin gruplar arası karşılaştırmalarında Bağımsız örnekler (İndependent samples) t testi kullanıldı. Íkiden fazla grup durumunda parametrelerin gruplar arası karşılaştırmalarında tek yönlü (One way) Anova testi ve farklılığa neden olan grubun tespitinde Tukey HSD kullanıldı ve sonuçlar \% 95 güven aralığında, anlamlılık $p<0.05$ düzeyinde çift yönlü olarak değerlendirildi.

\section{BULGULAR}

Vaka grubunun 45'i (\%75) anne, 15'i (\%25) baba; kontrol grubunun 54'ü (\%90) anne, 6’sı (\%10) baba idi.

Vaka grubunun 16 'sı (\%27) 20-29, 28'i (\%47) 30-39, 16 'sı (\%27) 40-49 yaş grubunda; kontrol grubunun 13'ü (\%22) 20-29, 37'si (\%62) 30-39, 10’u (\%17) 40-49 yaş grubunda idi.

Vaka grubunun 3'ü (\%5) bekâr, 57'si (\%95) evli; kontrol grubunun 7'si (\%12) bekâr, 53'ü (\%88) evli idi.

Vaka grubunun 26 'sı (\%43) ilkokul, 15'i (\%25) ortaokul, 12 'si (\%20) lise, 7'si (\%12) üniversite mezunu; kontrol grubunun $25^{\prime}$ i (\%42) ilkokul, 11'i (\%18) ortaokul, 14'ü (\%23) lise, 10’u (\%17) üniversite mezunu idi.

Vaka grubunun $19^{\prime}$ u (\%32) çalışıyor, 41'i (\%68) çalışmıyor; kontrol grubunun 24'ü (\%40) çalışıyor, 36'sı (\%60) çalışmıyor idi.

Vaka grubunun 18'i (\%30) 500-999 Türk Lirası (TL), 15’i (\%25) 1.000-1.499 Türk Lirası (TL), 13'ü (\%22) 1.500-1.999 Türk Lirası (TL), 11'i (\%18) 2.000-2.999 Türk Lirası (TL), 3’ü (\%5) 3.000 Türk Lirası (TL) ve üstü 
gelir düzeyine sahip; kontrol grubunun 20'si (\%33) 500-999 Türk Lirası (TL), 6’sı (\%10) 1.000-1.499 Türk Lirası (TL), 9’u (\%22) 1.500-1.999 Türk Lirası (TL), 16'sı (\%27) 2.000-2.999 Türk Lirası (TL), 9’u (\%15) 3.000 Türk Lirası (TL) ve üstü gelir düzeyine sahipti.

Vaka grubunda kendisinde psikiyatrik hastalık geçmişi olan $3(\% 5)$, ailesinde olan 7 (\%12) kendisinde olmayan 57 (\%95) ailesinde olmayan 53 (\%88) kişi; kontrol grubunda kendisinde psikiyatrik hastalık geçmişi olan 9 (\%15), ailesinde olan 4 (\%7) kendisinde olmayan 51 (\%85) ailesinde olmayan 56 (\%93) kişi idi.

Vaka grubunda 59 (\%98) kişi çocuk bakımını kendi, 1 (\%2) kişi başkası; kontrol grubunda 52 (\%87) kendi, 8 (\%13) başkası gerçekleştiriyordu.

Vaka grubunda psikolojik destek almak isteğine evet diyenlerin sayısı 19 (\%32), gerekirse evet diyenlerin sayısı 33 (\%55), hayır diyenlerin sayısı 8 (\%13); kontrol grubunda psikolojik destek almak isteğine evet diyenlerin sayısı 11 (\%18), gerekirse evet diyenlerin sayısı 36 (\%60), hayır diyenlerin sayısı 13 (\%22) idi.

BAÖ sonuçlarına göre vaka grubunda 20 (\%33) kişide anksiyete belirtileri yok, 40 (\%67) kişide ise 17'si (\%43) hafif, 11'i (\%28) orta 12'si (\%30) olmak üzere vardı. Kontrol grubunda 23 (\%38) kişide anksiyete belirtileri yok, 38 (\%62) kişide ise 23'ü (\%62) hafif, 5'i (\%14) orta 9'u (\%24) olmak üzere vardı.

BDÖ sonuçlarına göre vaka grubunda 28 (\%47) kişide depresyon belirtileri yok, 32 (\%53) kişide ise 16'sı (\%50) hafif, 12'si ( \%38) orta 4'ü ( \%13) olmak üzere vardı. Kontrol grubunda 30 (\%50) kişide anksiyete belirtileri yok, 30 (\%50) kişide ise 14'ü (\%47) hafif, 12 'si (\%40) orta 4'ü (\%13) olmak üzere vardı.

Araştırmaya katılanlardan çocukta kronik nörolojik hastalık olan vaka grubu $(n=60)$ ile sağlam çocukları olan ebeveynlerin oluşturduğu kontrol grubu $(n=60)$ depresyon ve anksiyete düzeyleri açısından karşılaştırıldığında anlamlı bir farklııık olmadığı görülmüştür ( $t=1.273$ p>0.05; Tablo 1).
Tablo 1. Araştırmaya katilanların anksiyete ve depresyon durumlarının çocukta kronik nörolojik hastalık olup olmamasına göre karşılaştırılması.

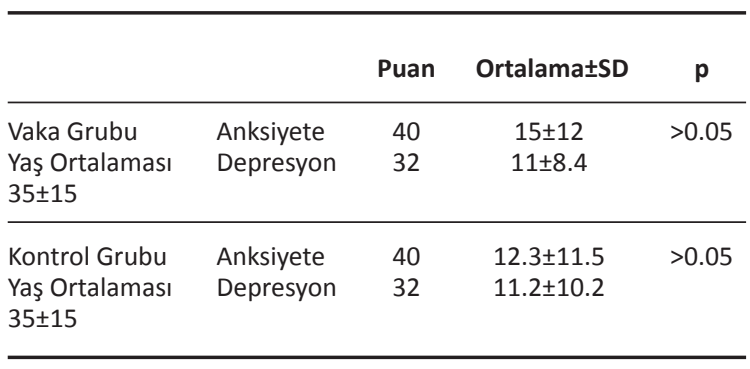

Vaka ve kontrol gruplarının hem anksiyete hem depresyon düzeylerinin arasında anlamlı bir farklılık olmayışı, ancak her iki grupta da hem anksiyete hem depresyonun yüksek oranda varlığı oldukça düşündürücüdür.

\section{TARTIŞMA}

Bu çalışmanın en önemli bulgusu; geçmişe oranla daha çok söz edilen ve daha çok önem verilen ruh sağlığı ve hastalıkları konusunun önemini bir kez daha bize göstermesidir.

Ruh sağlığı sorunları gelişmiş ve gelişmekte olan ülkelerde, her sosyoekonomik katmanda, her ırkta ve her kültürel grupta görülebilir. Dünya Sağlık Örgütü’ne göre, her dört kişiden biri ruhsal ya da nörolojik hastalık geçirme riski ile karşı karşıyadır.

Birçok ülkede yapılan toplum taramaları, ruhsal hastalıkların sanılandan çok daha yaygın olduğunu göstermektedir. Bu nedenle tüm ülkelerde ruh sağlığı sorunları, bir toplum sağ|ığı sorunu olarak kabul edilmektedir ${ }^{(12)}$.

Ruhsal bozuklukların toplumda yaygınlığıyla ilgili çalışmaları 3 grupta incelemek olasıdır:

1. İkinci Dünya Savaşı́ndan önce tüm ruhsal bozuklukların toplumdaki yaygınlık oranı eldeki kayıtlara göre \%3.6,

2. İkinci Dünya Savaşı'ndan 1970 'lere kadar mevcut kayıtlara göre $\% 20$ 'lerde,

3. 1970 'lerden itibaren yapılan çağdaş çalışmalarla $\% 30^{\prime}$ larda bulunmuştur ${ }^{(13)}$. 
Dünyada ruhsal hastalıkların sıklığı düşük yaygınlığı yüksektir. En çok yeti yitimine neden olan 10 hastalıktan 5'i ruhsal kaynaklıdır. ABD'de çocukların \%12'sinin, erişkinlerin \%15'inin bir ya da birden çok psikiyatrik bozukluğu olduğu saptanmıştır. Polikliniklere başvuran hastaların \%20-40'ı ruhsal sorunlartaşımaktadır. Türkiye Ruh Sağlığı Profil'i sonuçlarına göre, ruhsal hastalıklar toplumun \%17.2'sinde görülmektedir ${ }^{(14)}$.

Ülkemizde yapılan araştırmalarda, toplum içinde klinik düzeyde depresyon prevalansının \% 10 dolayında olduğu, genel olarak depresif belirtilerin toplum içindeki nokta prevalansının \%13-20 arasında olduğu gözlemlenmiştir ${ }^{(15)}$.

Anksiyete bozuklukları prevalansını araştıran en kapsamlı çalışmalardan biri Dünya Sağıık Örgütü’nün 1996 yılında sonuçlarını yayınladığı Sartorius ve ark.'nın ${ }^{(16)}$ yürüttüğü çalışmadır. On dört ülkede 15 merkezde yürütülen, 25.000 erişkinin psikiyatrik bozukluklar açısından tarandığı çalışma sonucunda anksiyete bozuklukları prevalansı \%10.5 bulunmuştur. En yüksek prevalans depresyona ait olup, \%11.7'dir. Hem anksiyete hem depresyonun birlikte olduğu karışı (mixed) tabloların prevalansı ise bu çalışmada \%4.6 olarak belirlenmiştir.

Bizim çalışmamızda, katılımcıların hasta ya da sağlıklı çocuk ebeveyni olup olmadığı dikkate alınmaksızın genel olarak yüksek değerlerde anksiyete ve depresyon düzeyine sahip oldukları dikkati çekmiştir.

Çalışmamızda, genel olarak toplumda görülme sıklığı olarak verilen değerlerden daha yüksek düzeyde anksiyete ve depresyon görülme sebeplerinden olası birinin araştırmaya katılanlar ile sağlık hizmeti almak üzere bir sağlık merkezinde bulundukları sırada görüşülmüş olması olabileceği düşünülmektedir. Bu durum da gözönüne alınarak sağlıklı çocuk anne babası olarak belirtilen kontrol grubu için bir alışveriş ya da tatil merkezi gibi daha rahat hissedilen ortamlarda bulunan kişilerle de karşılaştırma amaçlı çalışmakta yarar olabilir.
Sonuç olarak, araştırmaya katılan hasta çocuğa sahip olan anne-babaların depresyon ve anksiyete düzeyleri hasta olmayan çocuğa sahip anne babaların depresyon ve anksiyete düzeylerinden anlamlı bir farklılık göstermedi. Ancak her iki grupta da depresyon ve anksiyete varlığı yaklaşık olarak aynı derecede yüksek bulundu.

Dolayısıyla, hasta çocukların ebeveynlerinde depresyon ve anksiyete oranının içinde bulunulan duruma bağlı olarak yüksek olduğunu göstermek ve psikolojik destek gereksiniminin gerekliliğine dikkat çekmek olan bu çalışmanın amacını daha da genelleştirmek gerektiği, ruh sağlığı hizmetlerinin toplumun her kesimine kolayca erişebilecekleri şekilde sunulmasına gereksinim olduğu ortaya çıktı. Bu şekilde toplumsal sorunlara daha kısa sürede daha sağlıklı çözüm bulmanın ve zamandan, para ve işgücünden kazanç sağlamanın mümkün olacağı düşünülmektedir. Ayrıca konu hakkında daha ayrıntılı araştırmalar yapmak gerekliliği ortaya çıkmıştır.

Etik Kurul Onayı: İstanbul Üniversitesi Tıp Fakültesi Etik Kurulu tarafından onay alınmıştır (Tarih: 15.04.2013, Sayı: 405, Dosya no: 2013/383)

Çıkar Çatışması: Yazarlar arasında çıkar çatışması yoktur.

Finansal Destek: Herhangi bir finansal destek alınmamıştır.

Hasta Onayı: Tüm hastalardan aydınlatılmış hasta onayı alınmıştır.

Ethics Committee Approval: Approval from the Ethics Committee of Istanbul University Faculty of Medicine (Date: 15.04.2013, No: 405, File no: 2013/383)

Conflict of Interest: There is no conflict of interest between the authors.

Funding: No financal support was received.

Informed Consent: Informed consent was obtained from all patients. 


\section{KAYNAKLAR}

1. Vardar i. Toplumsal Tramva. http://ilhanvardar.blogspot.com/2013/03/toplumsal-tramva.html

2. Toros F, Tot Ş, Düzovalı Ö. Kronik hastalığı olan çocuklar, anne ve babalarındaki depresyon ve anksiyete düzeyleri. Klinik Psikiyatri. 2002;5:240-7.

3. Emiroğlu Ni, Akay AP. Kronik hastalıklar, hastaneye yatış ve çocuk. DEÜ Tıp Fakültesi Dergisi 2008;22:99105.

4. Çığrıkçı H. Kronik hastalığı nedeniyle devamlı takip edilmekte olan çocukların annelerinin sosyodemografik özellikleri ve annelerin depresyon prevalansı. Yayınlanmamış Uzmanlık Tezi, T.C Sağlık Bakanlığı Bakırköy Dr. Sadi Konuk Eğitim ve Araştırma Hastanesi, Aile Hekimliği Koordinatörlüğü İstanbul: 2014.

5. Işık E, Taner Y. Çocuk Ergen ve Erişkinlerde Anksiyete Bozuklukları. Asimetrik Parelel Kitabevi. 2006;s.3-29.

6. Dadalı Z. Hemodiyaliz ve Prediyaliz Hastalarında Anksiyete, Depresyon ve Yaşam Kalitesinin Karşılaştırılması (Yayınlanmamış Uzmanlık Tezi). Bakırköy Prof Dr. Mazhar Osman Ruh Sağlığı ve Sinir Hastalıkları Eğitim ve Araştırma Hastanesi, İstanbul: 2009.

7. Çevik A, Volkan VD. Depresyonun psikodinamik etiyolojisi. Depresyon Monografları Serisi, 1993:3:109-22.

8. Ünal FE. Bakırköy Dr. Sadi Konuk Eğitim ve Araştırma
Hastanesinde Çalışan Tıpta Uzmanlık Öğrencilerinde Depresyon ve Anksiyete Sıklığının Saptanması v Sosyodemografik Faktörlerin Araştırılması, Yayınlanmamış Uzmanlık Tezi, T.C Sağlık Bakanlığı Bakırköy Dr. Sadi Konuk Eğitim ve Araştırma Hastanesi, İstanbul: 1993.

9. Gorman JM. Comorbid depression and anxiety spectrum disorders. Depress Anxiety. 1996;4:160-8.

10. Er M. Çocuk, hastalık, anne-babalar ve kardeşler. Çocuk Sağlığı ve Hastalıkları Dergisi. 2006;49:155-68.

11. Aydoğan A. Özürlü çocuğa sahip ailelerde umut düzeyinin belirlenmesi. Hacettepe Üniversitesi Doktora Tezi. 1999;S.121-7.

12. Güleç C. Toplum ruh sağlığı açısından psikiyatrik epidemiyoloji. Halk Sağlığı Temel Bilgiler, Ankara, Güneş Kitabevi. 1995;S.442-53.

13. Çelikkol A. Koruyucu ruh sağlığı. Ege Üniversitesi Tıp Fakültesi Psikiyatri ABD ders notları. İzmir. Ege Üniversitesi Yayın Bürosu. 2001;s.151-2.

14. Öniz A. Temel sağlık hizmetleri ve ruh sağlığı seminer notları, 2001. İzmir Halk Sağlığı Müdürlüğü

15. Öztürk O. Ruh sağlığı ve bozuklukları. 6. baskı. Ankara, Hekimler Yayın Birliği, 1997.

16. Sartorius N, et al. Depression comorbid with anxety: results from the WHO study on psychological disorders in primary health care. Br J Psychiatry Suppl, 1996. 